\title{
Non-steady state approach to the vacuum nitriding for tools
}

\author{
Piotr Kula, Emilia Wolowiec*, Robert Pietrasik, Konrad Dybowski, Bartłomiej Januszewicz \\ Institute of Materials Science and Engineering, Lodz University of Technology, 1/15 Stefanowskiego Street, Lodz 90-924, Poland
}

\section{A R T I C L E I N F O}

\section{Article history:}

Received 27 March 2012

Received in revised form

31 July 2012

Accepted 2 August 2012

\section{Keywords:}

Vacuum nitriding

Nitrides

Tool steels

Neural networks

\begin{abstract}
A B S T R A C T
A method to the control of vacuum nitriding process that could be applicable for a variety of tool steels is presented. The quantitative diffractometric X-ray phase analysis has been applied to identify the nitrides growth and their stoichiometry as the function of steel composition, nitriding parameters and time. It has been found that the nitrogen content in the $\varepsilon$ nitride depends not only on the nitriding parameters but it is also strongly influenced by alloying elements in steel. This statement has practically excluded using any steady state models to control and monitor the precise nitriding of alloy steels, especially in the case of vacuum nitriding of tool steels. The importance of the nucleation stage for repeatability of vacuum nitriding results has been shown, too. The effective method for active washing of charge is demonstrated and proposed to unify and shorten nucleation time. Finally, the neural network model is presented as a new approach to modelling and control of the non-steady state vacuum nitriding of various tool steels. This model is based on the "boost-diffusion" schedule of the process.
\end{abstract}

(c) 2012 Elsevier Ltd. All rights reserved.

\section{Introduction}

Contemporary tools for machining and dies for forging, forming and die casting require several subsequent operations of advanced vacuum heat treatment and surface engineering, namely, quenching, tempering, nitriding and PVD coating. The ability to carry out some of these operations in the same device would make the manufacturing much easier and cheaper. There have been several reports about attempts at coupling the ion nitriding and PVD plating in the same vacuum chamber [1-4]. Contemporary multipurpose vacuum furnaces are able to integrate precise austenizing, high pressure gas quenching, single or multiple tempering and also low pressure nitriding [5-8]. However, a reliable low pressure nitriding requires the development of models and technology for a variety of alloying tool steels due to high microstructural demands from nitrided cases on tools.

The idea of low vacuum nitriding has been regarded since 60 s of $\mathrm{XX}$ century as an alternative for the conventional gas nitriding. The reason behind this concept was the want of better controllability of a nitrogen flux to steel. Smirnov and Kulesov have presented the equilibrium diagram "dissociation degree of ammonia - pressure solid phases of iron-nitrogen system" [8]. They showed that

\footnotetext{
* Corresponding author. Tel.: +48 4263122 79; fax: +48 426366790.

E-mail addresses: piotr.kula@p.lodz.pl (P. Kula), e.wolowiec@wp.eu, emilia.wolowiec@p.lodz.pl (E. Wolowiec), robert.pietrasik@p.lodz.pl (R. Pietrasik), konrad.dybowski@p.lodz.pl (K. Dybowski), bartlomej.januszewicz@p.lodz.pl (B. Januszewicz).
}

decreasing the pressure below the atmospheric one causes a displacement of equilibrium towards phases $\varepsilon$ and $\gamma^{\prime}$ which contain more nitrogen. Krylov proposed to make use of a steep part of the Langmuir isotherm (below ca. $100 \mathrm{hPa}$ ) to monitor nitrogen flux during low pressure nitriding [9]. In this way, he suggested the change of approach to control and monitoring of low pressure nitriding from the thermodynamic mode based on the control of nitrogen potential to the kinetic mode based on the control of adsorption degree. This fundamental statement was the base for development of several vacuum nitriding procedures which have been applied in practice [10]. All these processes have been worked out by experimental trial and error method. There is the need to develop the theoretical models of non-steady state vacuum nitriding for a variety of alloy tools steel to enlarge the application range of this low pressure process towards advanced dies and tools for forging, forming, die casting and machining. These models might be incorporated into the control and monitoring systems of multipurpose vacuum furnaces.

Also a very important question, is the surface preparation by chemical etching. In the case of applied process parameters, namely nitriding pressure at level 26 mbar (what is connected with technological and safety requirements of industrial installations), the degree of surface development is the most important factor, as Smirnov and Kuleshov present in their researches. Therefore part 3.2 presents a solution for new activating-cleaning baths which create appropriate surface and are environmental friendly by elimination of highly un-green $\mathrm{FeCl}_{3}$. 


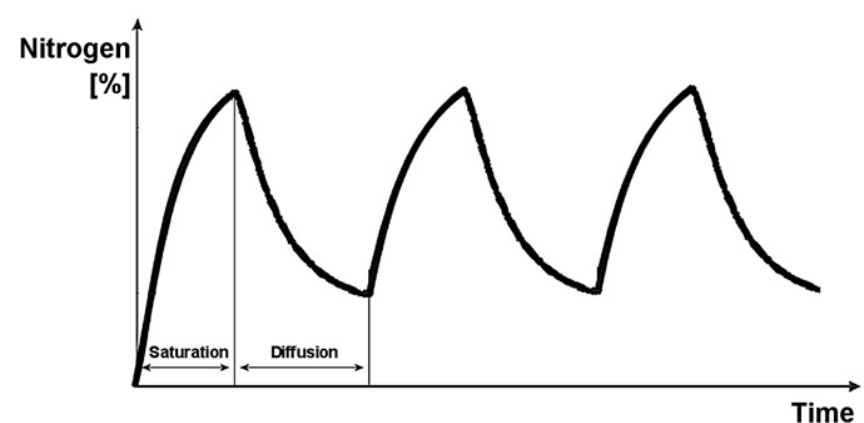

Fig. 1. The low pressure nitriding process exemplary schedule.

Most processes of thermo-chemical treatment are preceded by the surface preparation procedures. Apart from cleaning and degreasing, the surface activation is used: i.e. by mechanical stimuli (e.g. surface deformation), chemical (e.g. phosphate coating) or physical treatment (e.g. cathode sputtering in glow discharge).

In the nitriding process, physicochemical interactions between the adsorbed substance and solid surface layer determines the capacity and mechanism of nitrogen atoms penetrating the barrier of surface.

The real surface of working pieces is more or less rough, structurally heterogeneous, and covered with a layer of chemical compounds being in most cases metal oxides and traces of alloy elements. All these factors influence the adsorption process and the equilibrium and mechanism of chemical reactions which take place on the surface of treated charge. The privileged sites for the initiation of chemical reactions are the areas with defective structure with high internal energy, as well as the discontinuities in the passive layer. There, the chemical reactions proceed more intensively as compared to the rest of the surface and, consequently, atoms of the saturating element penetrate into the material surface, frequently determining a new site for the nucleation phase development.

In the case of thermo-chemical treatment of carbon and lowalloy steels the surface oxides film is not a substantial obstacle to observing the mechanisms of diffusion saturation of surface layers. These layers are composed solely of iron oxides, which are easily reduced in the initial stage of the process. In the case of alloyed tool steels, chromium is the dominant alloying element. The tightness and chemical stability of passive oxide films increase with its higher content in the steels $[17,18]$. Therefore, to overcome the barriers of passivity in the process of medium- and high alloy steel nitriding, it is necessary to activate the surface. Otherwise, uneven layers are created, and sometimes insular structures, especially for short time processes, can be observed. Without activation, the time needed for phase nucleation process is significantly longer. It is an unnecessary delay in the production of a relatively thin nitrided layers on the tools.

Precise controlling and possibility of designing of the process course are the must in modern thermo-chemical treatment. The best solution, as the practice and theory indicate, is computer aided design based on neural networks. Application of neural networks requires creation of comprehensive experimental database, based on knowledge of physic-chemistry of the process, thus problems of nucleation and surface preapration are presented in the article.

The "boost-diffusion" model has been proposed to control and monitor low pressure nitriding of tools in multipurpose vacuum furnaces. The basic assumptions for this model are:

- all "boost" stages are carried out at the constant total pressure of $26 \mathrm{hPa}$, at the ammonia supplying flow that is proportional to the total area of nitrided charge. The level of pressure is in conformity with the industrial safety requirement. This assumption should guarantee the constant and repeatable nitrogen content in optional $\varepsilon$ phase on treated steel grades during the "boost" stages rich in nitrogen,

- all "diffusion" stages are carried out in vacuum to separate the nitrogen reserve in nitrides from any external interactions. It enables the reliable modelling of nitrogen diffusive transfer based only on disproportionation and decomposition of nitrides' zone.

An exemplary schedule of "boost-diffusion" low pressure nitriding is shown on the Fig. 1.

At present there is no physical theory or model that gives the correlations for the path of processing of vacuum nitriding parameter-microstructure-properties for tool steels. For that reason the statistical approach seems more appropriate. The statistical models can be applied in areas where large quantities of data exist and there are no physical models to describe the process.

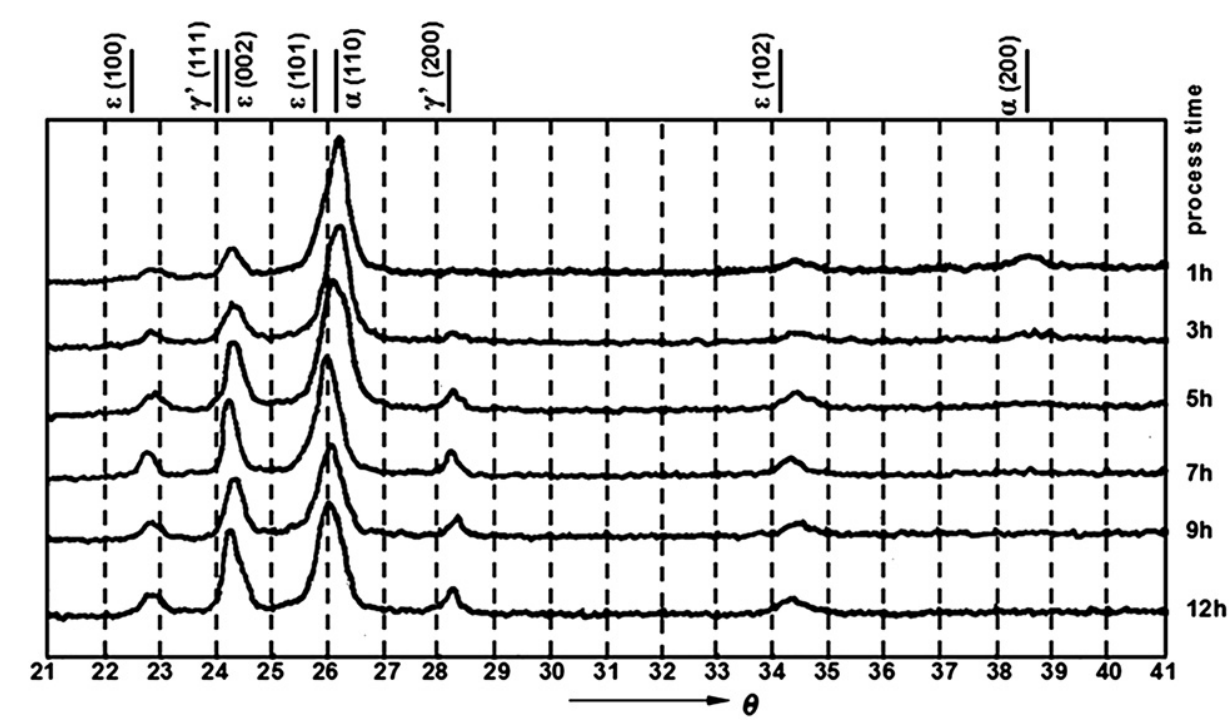

Fig. 2. Diffractograms registered for preparation of powder steel after gas nitriding at a temperature of $813 \mathrm{~K}$, the degree of dissociation of ammonia $K=25 \%$. 


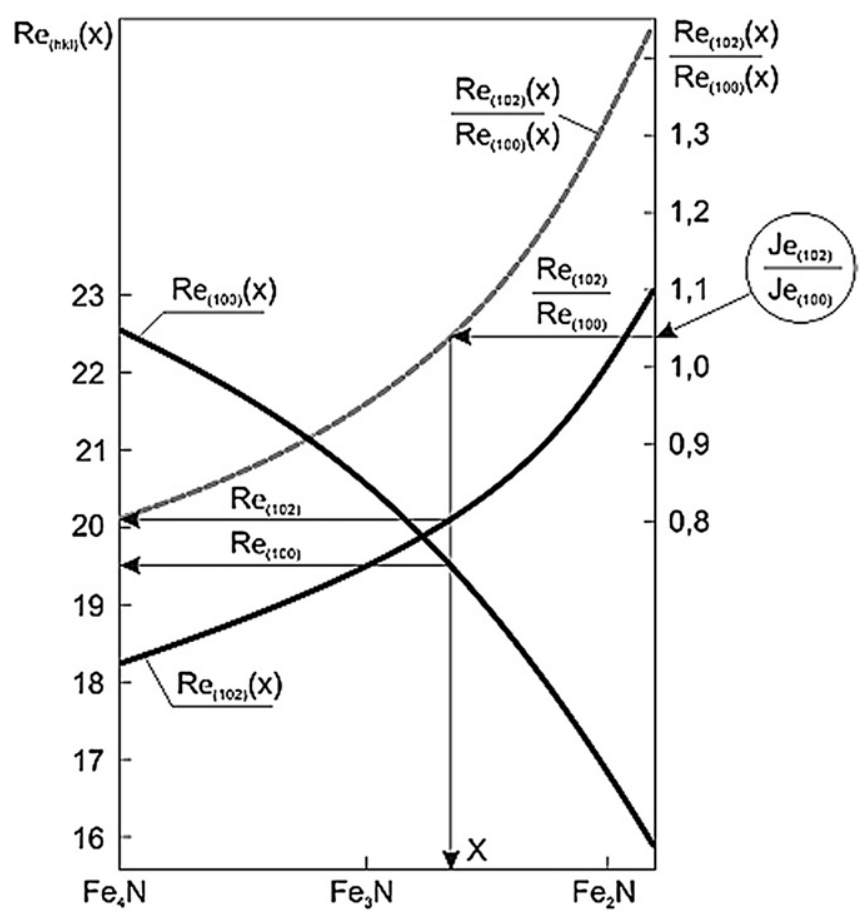

Fig. 3. The relationship between "x-ray" intensity factors $R_{\varepsilon(100)}, R_{\varepsilon(102)}$ and their ratio as function of nitrogen concentration in the $\varepsilon$. Arrows show how to use the diagram.

\begin{tabular}{|c|c|c|c|c|c|}
\hline \multicolumn{2}{|c|}{ Label } & \multicolumn{5}{c|}{$\mathrm{pH}$} \\
\cline { 3 - 6 } \multicolumn{2}{|c|}{} & 6,5 & 6,2 & 5,8 & 5,5 \\
\hline $\begin{array}{c}\mathrm{Cl}-\text { - ion } \\
\text { concentration } \\
{\left[\mathrm{mol} / \mathrm{dm}^{3}\right]}\end{array}$ & 0,12 & $\mathbf{1}$ & $\mathbf{2}$ & $\mathbf{3}$ & $\mathbf{4}$ \\
\cline { 2 - 6 } & 0,62 & $\mathbf{5}$ & $\mathbf{6}$ & $\mathbf{7}$ & $\mathbf{8}$ \\
\hline
\end{tabular}

Fig. 4. The labels of activation parameters for structures presented in Fig. 9.

Artificial neural network are currently among the most powerful modelling techniques based on a statistical approach [19-22], and thereby they are considered a proper tool on modelling the problem discussed.

\section{Experimental}

\subsection{Nitrogen transfer vs. gas composition, pressure and alloying}

Any alloying influences an equilibrium and kinetics of nitriding. This is a complex problem, therefore, up to now monitoring systems for nitriding of alloy steels were based on applying experimental correction factors to analytical equations for nitrogen - iron system [11-14]. This is a simplified approach and it is absolutely not descriptive for higher alloying steels and low pressure conditions.

The specimens were prepared in the form of thin turning chips (ca. $0.1 \mathrm{~mm}$ thick) made of $41 \mathrm{CrAlMo} 7$ steel. Standard $(p=1000 \mathrm{hPa})$ and low pressure nitriding processes $(p=100 \mathrm{hPa})$ were carried out in the experimental device which enabled to keep the fixed and constant degree of ammonia dissociation (25\%, 50\% and $75 \%$ ). The nitriding times from 1 to $12 \mathrm{~h}$ with step $1 \mathrm{~h}$ were applied. Similar vacuum nitriding series was done for turnings specimens which had been previously sulphontrided [15] to activate the surface for a subsequent vacuum nitriding. Specimens were fast quenched in the liquid nitrogen immediately after nitriding to retain the original phase composition from the nitriding temperature $(813 \mathrm{~K})$. The nitrogen concentration in specimens was determined by "wet" chemical analysis as well as the quantitative XRD analysis was conducted to determine the phase composition after nitriding. The $\mathrm{C}_{\mathrm{K} \alpha}$ radiation was applied in the angle range $\Theta<21^{\circ}, 41^{\circ}>$ (Fig. 2). The original method was used to determine a non-stoichiometry factor for the $\varepsilon\left(\mathrm{Fe}_{\mathrm{X}} \mathrm{N}\right)$ iron nitride. This method is based on the comparison of intensity for $\varepsilon(100)$ and $\varepsilon(102)$ reflections on XRD spectra (Fig. 3) according to equation [16].

$I_{x}=\frac{K_{2} R_{x} C_{x}}{2 \mu}$

where: $K_{2}-$ constant, independent of the type and amount of test substance, $R_{X}$-factor depending on the type of substance, the angle $\theta$ and Miller indices (hkl), $C_{x}$ - phase volume fraction in the mixture, $\mu$-linear absorption coefficient.

It must be noted that the necessary condition of application of the quantitative analysis is that the each phases must be represented by at least one free peak. The intensity of the radiation line was determined by planimetric method based on area under the peak.

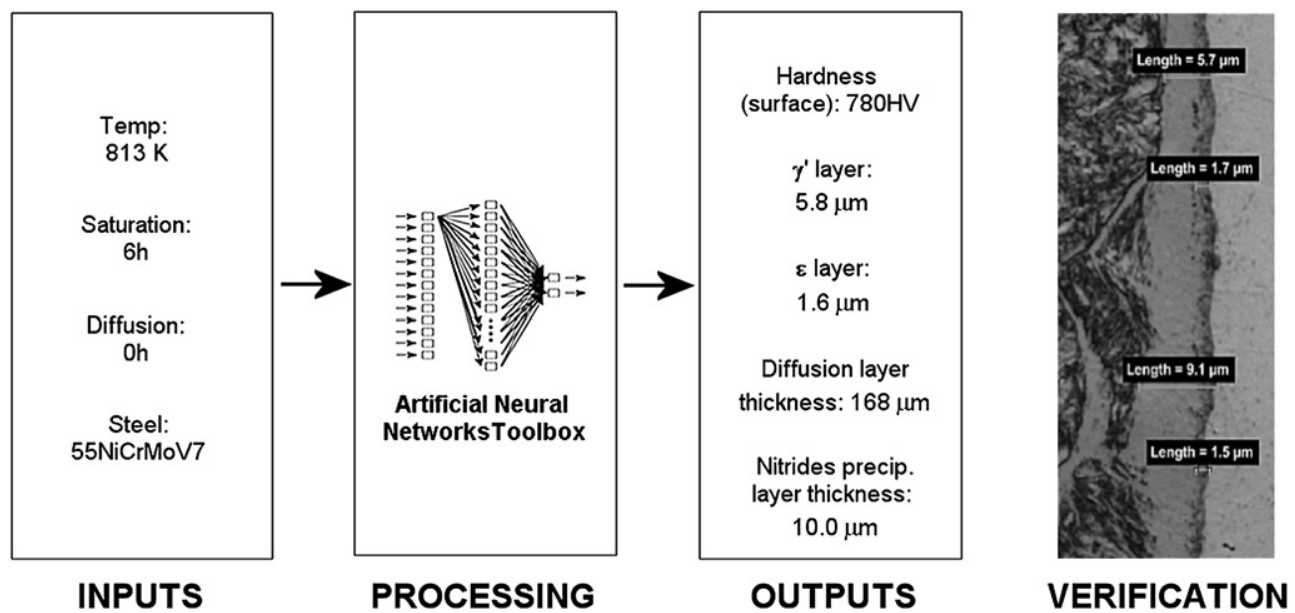

Fig. 5. Processing diagram of artificial neural network. Verification: optical microscopy images, samples were etched by $4 \% \mathrm{HNO}_{3} / \mathrm{ethanol}$. 

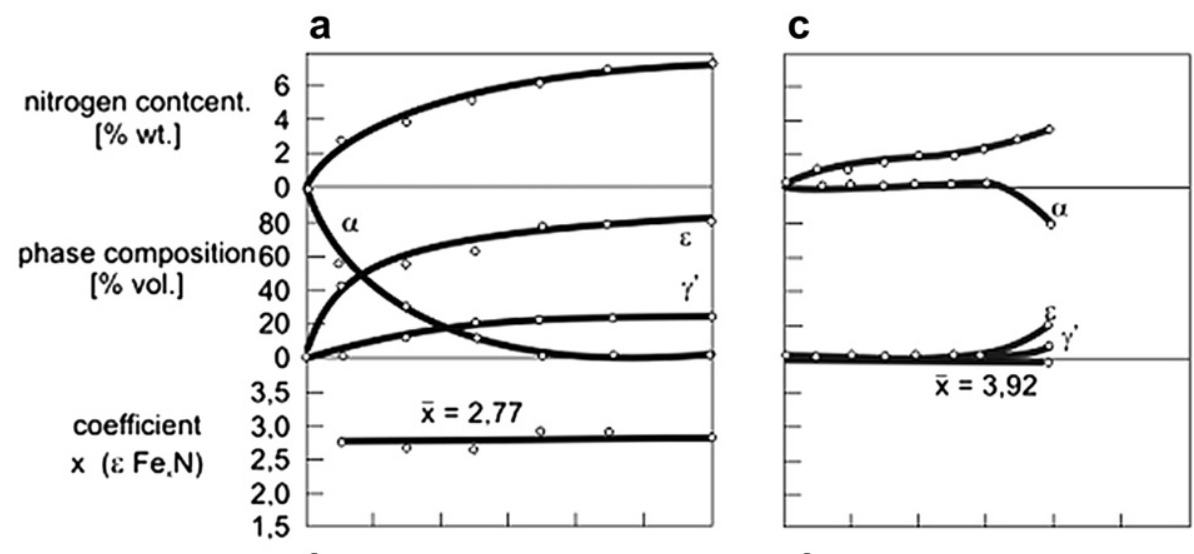

b

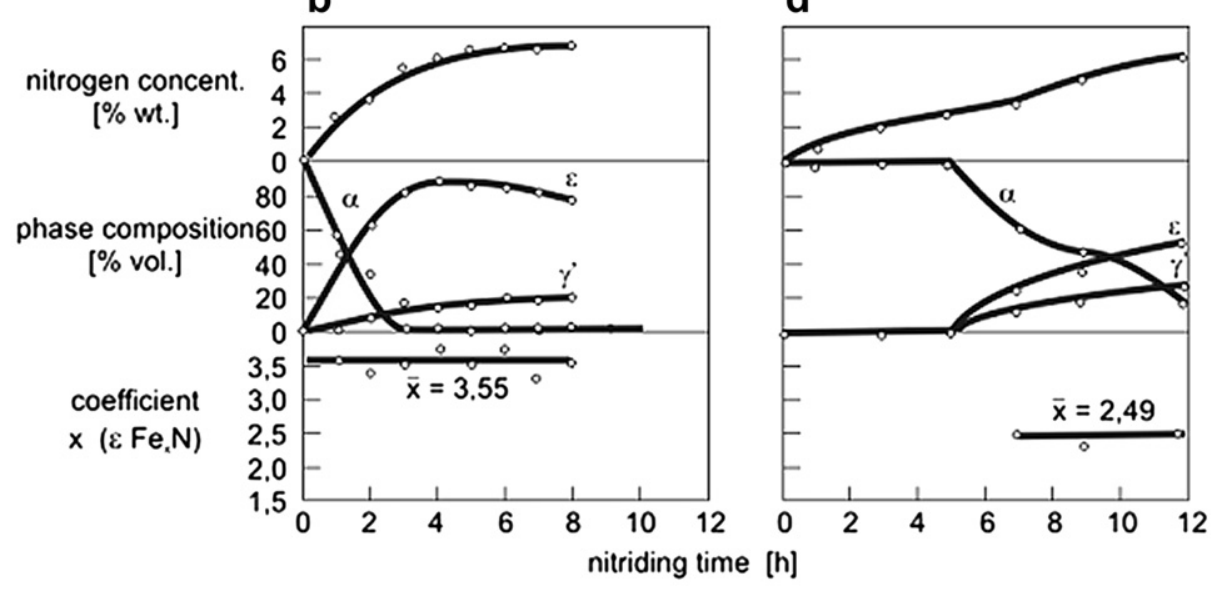

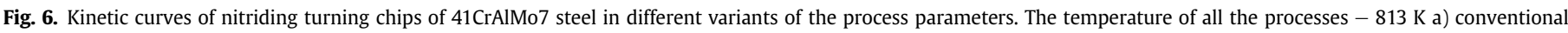
nitriding at $K=25 \%$; b) conventional nitriding at $K=50 \%$; c) conventional nitriding at $K=75 \%$; d) nitriding at decreased pressure ( $p=100$ hPa, $K=25 \%$ ).

The same method has been used to determine the " $\mathrm{x}$ " nonstoichiometry factor of $\varepsilon\left(\mathrm{Fe}_{\mathrm{x}} \mathrm{N}\right)$ iron nitride zone for several bulk specimens made of different steel grades (pure iron, C55, 16CrMn5, $42 \mathrm{CrMo} 4$ and $\mathrm{X} 210 \mathrm{Cr} 12$ ) treated by conventional gas nitriding.

\subsection{Nucleation stage}

To speed up the process and to homogenize the structure, the new activation bath was developed and used in the washing step after degreasing of elements. Activation stage is necessary to ensure

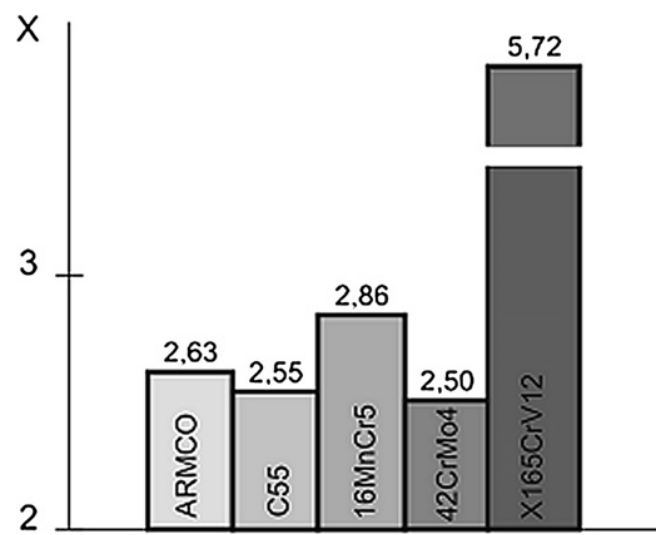

Fig. 7. Value of " $\mathrm{x}$ " coefficient $\left(\varepsilon \mathrm{Fe}_{\mathrm{x}} \mathrm{N}\right)$ attained on various kinds of steels after conventional gas nitriding. repeatability of received results. It is required for the usage of those results in the process of simulation. Activation process has been merged with washing before nitriding. Appropriate bath ingredients were selected in order to ensure its efficiency and the same time, environmental performance.

The importance of this step in the nitriding process is illustrated at Fig. 9. It shows the nitrided layers obtained on steel $\mathrm{X} 155 \mathrm{CrVMo12}$, for the varied bath $\mathrm{pH}$ and active ions concentration. The labels of activation parameters were placed in Fig. 4, the digit 9 means no sample activation was done.

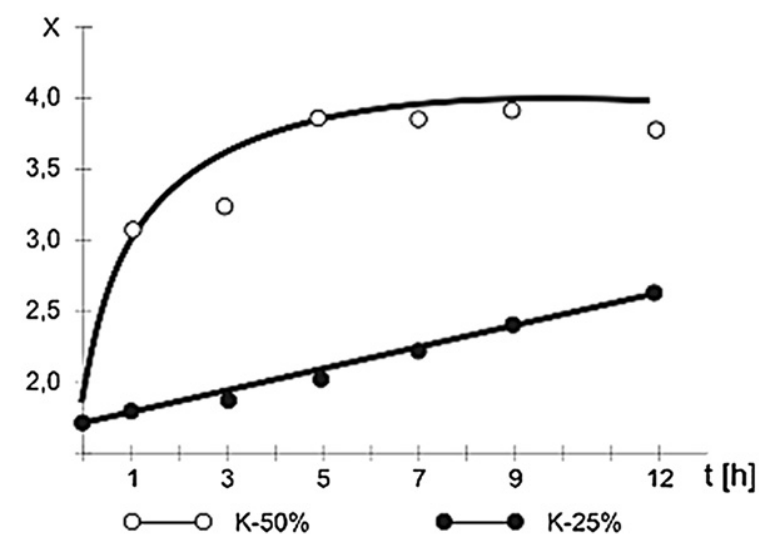

Fig. 8. Kinetics of nitrogen contents changes in $\varepsilon$-phase in 41CrAlMo7 steel samples in the turnings form. Temperature $-813 \mathrm{~K}$, pressure $-100 \mathrm{hPa}$. 


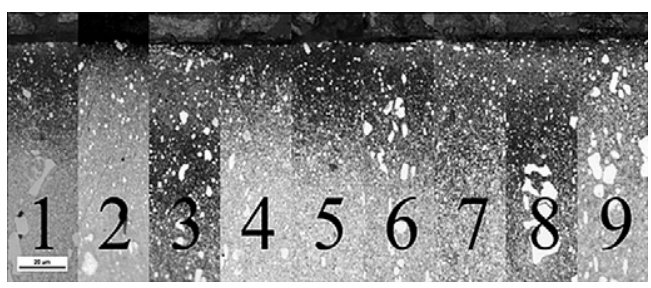

Fig. 9. Structure of the nitrided layers after different activations on X155CrVMo12 steel. Temperature $-813 \mathrm{~K}$, time $-3 \mathrm{~h}$. Optical microscopy images, samples were etched by $4 \% \mathrm{HNO}_{3} /$ ethanol.

\subsection{Neural network approach}

By analysing experimental processes of low pressure nitriding, the following parameters were considered significant: process temperature, boost segment time, diffusion segment time and chemical composition of the material. In order to prepare learning templates for the network, besides the said parameters, hardness on sample's surface, total layer thickness, $\varepsilon$ phase layer, $\gamma^{\prime}$ phase layer and nitrides layer thickness were additionally archived.

Several dozen architectures with varied number of hidden neurons and characterized by different activation functions (linear, sigmoid, tangential and exponential functions) were tested. The
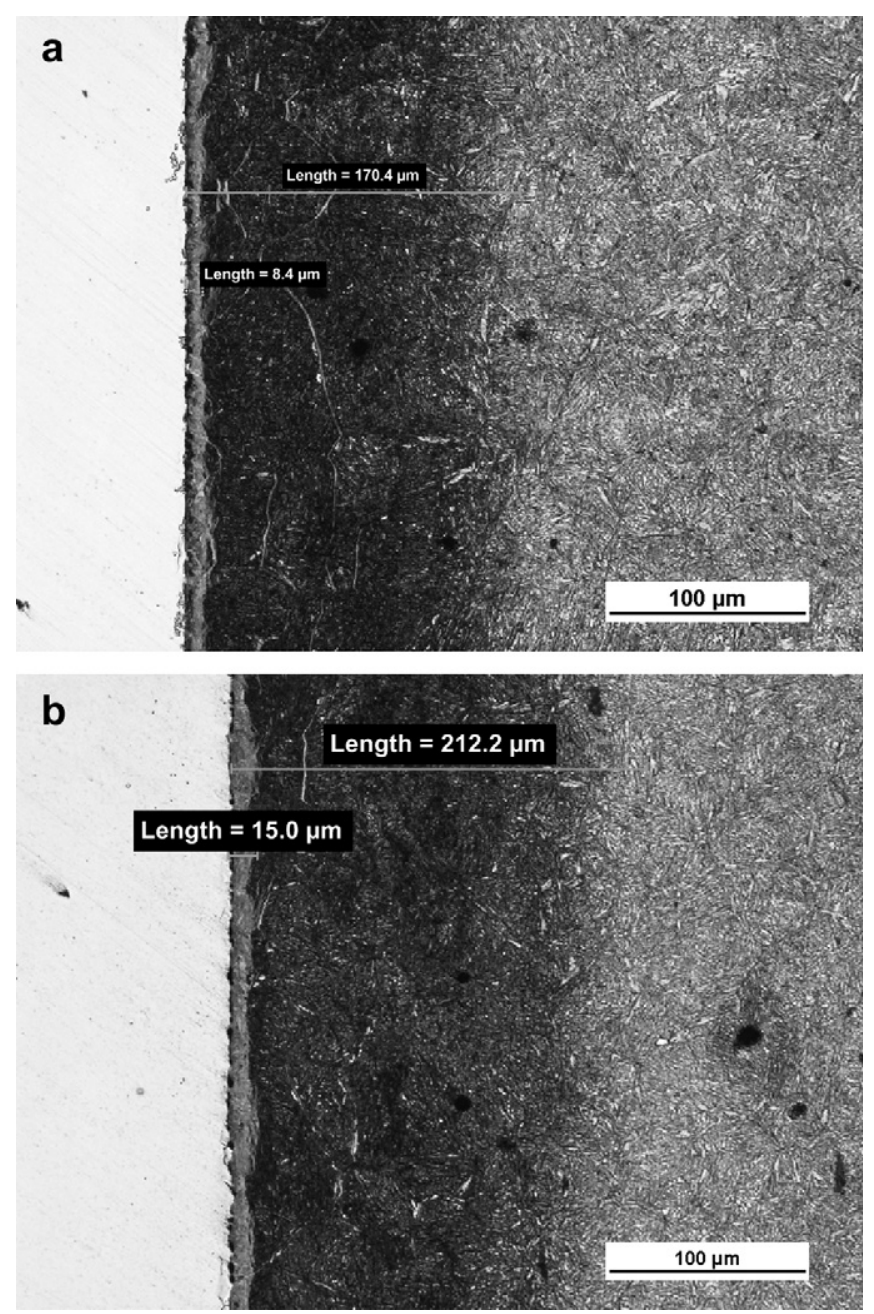

Fig. 10. Morphological structure of $\mathrm{X} 37 \mathrm{CrMoV} 51$ after continuous low pressure nitriding in temp. $833 \mathrm{~K}$ for a) $4 \mathrm{~h}$, b) $6 \mathrm{~h}$. Optical microscopy images, samples were etched by $4 \% \mathrm{HNO}_{3} /$ ethanol.
Fig. 6 presents a diagram of the final conception with using five MLP neural networks (MultiLayer Perceptron-a feed forward artificial neural networks) that was examined. The networks had 10 inputs (\%C, \%Si, \%Mn, \%Cr, \%Mo, \%Ni, \%V, Temp [K], Saturation [hour], Diffusion [hour]), 1 outputs, and 25 to 34 of neurons in hidden layer. The BFGS algorithm (the Broyden-Fletcher-Goldfarb-Shanno method for solving nonlinear optimization problems, presented in [23-25]) turned out to be the best training method for the network selected Fig. 5.

\section{Results and discussion}

\subsection{Nitrogen transfer vs. gas composition, pressure and alloying}

The results of structural and chemical analyses for the first series of turning specimens are presented on the collective diagram (Fig. 6). All kinetic curves - both those for nitrogen content and those for nitrides ratio - have the parabolic shape. Although the turnings form specimens were very thin, no equilibrium of phase compositions was reached for any value of the nitrogen potential. Numerous kinetic factors like slow adsorption, slow nitrogen transfer through interfaces etc. and/or complex residual stresses might cause this behaviour. However, it is noteworthy that the nitrogen content in $\varepsilon\left(\mathrm{Fe}_{\mathrm{X}} \mathrm{N}\right)$ iron nitrides is constant throughout the
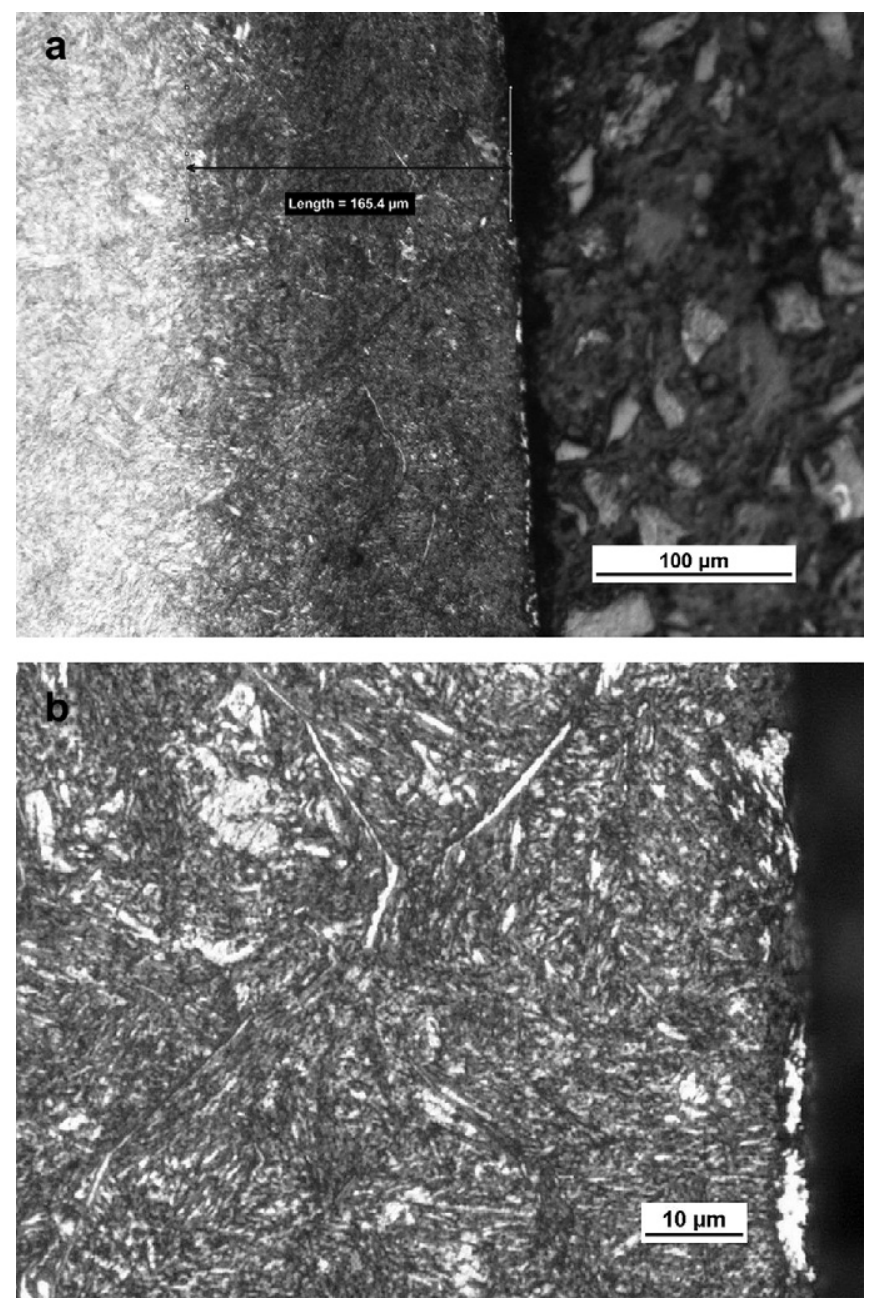

Fig. 11. Morphological structure of X37CrMoV51 steel nitrided in temp. $833 \mathrm{~K}$ in a twosegment process, with a 4-h segment of quenching and a 2-h segment of diffusion. The surface hardness achieved in the process: 921HV10. Optical microscopy images, samples were etched by $4 \% \mathrm{HNO}_{3} /$ ethanol. 
processes at constant nitrogen potential $-K_{\mathrm{N}}$. This confirms that the nitrogen concentration in $\varepsilon$ phase is in equilibrium with the nitriding atmosphere immediately after it appears. It is also apparent that even a small addition of alloying elements to the $41 \mathrm{Cr}$ AlMo7 steel extends the range of the $\varepsilon$ phase existing towards lower nitrogen contents (Fig. 6 b,c). The influence of alloying on the nitrogen concentration in $\varepsilon$ phase has been also confirmed on the gas nitrided bulk specimens made of various steel grades (Fig. 7). Although the nitrogen concentrations in $\varepsilon$ phase on iron, plain carbon steel and low-alloy steels differ, they are still in the range of the $\varepsilon$ phase existing in $\mathrm{Fe}-\mathrm{N}$ equilibrium diagram. In the case of the high chromium tool steel (X210Cr12), the $\varepsilon$ phase contains much less nitrogen (according to $\mathrm{Fe}_{5,78} \mathrm{~N}$ stoichiometric formula) in the same nitriding conditions. The comparison of " $\mathrm{x}$ " factors for $\varepsilon$ phases which has been obtained at the same gas composition $(25 \%$ of $\mathrm{N}_{2}+\mathrm{H}_{2}$ ) and at different total pressures (Fig. $6 \mathrm{a}, \mathrm{c}$ ) confirms that decreasing total pressure displaces the equilibrium towards phases richer in nitrogen.

The nitrogen content in $\varepsilon$ phase is an important source of nitrogen during "poor" stages of non-steady state, multistage nitriding processes. Therefore, being aware of very strong and multifactor dependence of " $x$ " factor on a nitriding gas composition, total pressure of it and especially on alloying system and its order should be the important fundamentals for development of new non-steady state models for vacuum nitriding of tool steels. Also, the kinetics of $\varepsilon$ phase decomposition plays an important role in these models of vacuum nitriding. Fig. 8 shows the disproportionation rate of nitrogen rich $\varepsilon$ phase $(x=1,5)$ that has been previously created on turning form specimens of the $41 \mathrm{CrAlMo} 7$ steel by short sulphonitriding. If the nitrogen potential (corresponding to $P=100 \mathrm{hPa}$ and $25 \%$ of $\mathrm{N}_{2}+\mathrm{H}_{2}$ ) of gaseous phase is close to the nitrogen content in $\varepsilon$ phase its disproportionation is slow and linear and probably all nitrogen from $\varepsilon$ phase is transferred to the interior of steel according to the diffusion laws. Conversely, if the nitrogen potential (corresponding to $P=100 \mathrm{hPa}$ and $50 \%$ of $\mathrm{N}_{2}+\mathrm{H}_{2}$ ) of gaseous phase is much lower than the nitrogen content in the $\varepsilon$ phase corresponding to it at that moment, its disproportionation proceeds rapidly along a parabolic curve until a temporary equilibrium is reached. Then part of nitrogen returns from $\varepsilon$ phase to the gaseous phase. Those are two absolutely different physical behaviours from the point of view of non-steady state modelling for vacuum nitriding.

\subsection{Nucleation stage}

Experiments carried out for X155CrVMo12 steel showed that the best bath, from the view point of morphology of the surface layer obtained after vacuum nitriding, is bath of $\mathrm{pH}=5.5$ and $\mathrm{Cl}^{-}$ ion concentration equal $0.62[\mathrm{~mol} / \mathrm{dm} 3]$. This layer was characterised by the biggest depth and uniformity (Fig. 9). The new solution for activation of the surface before process of nitriding allows shortening the process and increasing the depth of nitrogen atoms penetration by removing the oxides, contaminations and surface development.

As a result, the optimal activating bath was selected, taking into account the efficiency of the process and its environmental impact.

\subsection{Neural network approach}

The process of training the network used the experimental data on four tool steels: X155CrVMo12, HS 6-5-2, X37CrMoV51, $55 \mathrm{NiCrMoV7}$. The materials were selected such that nearly all the elements present in the tool steels should be taken into account at the training stage and the network forecasts can be extrapolated beyond the training base.

Example verification of the model was carried out on X37CrMoV51 steel. Due to the specific mode of a mould operation, the thickness of the nitride layer $\gamma^{\prime}$ after the nitriding process did not exceed $2 \mu \mathrm{m}$ and the presence of phase $\varepsilon$ is unacceptable. The expected thickness of the layer $-0.15 \div 0.18 \mathrm{~mm}$. It is difficult to
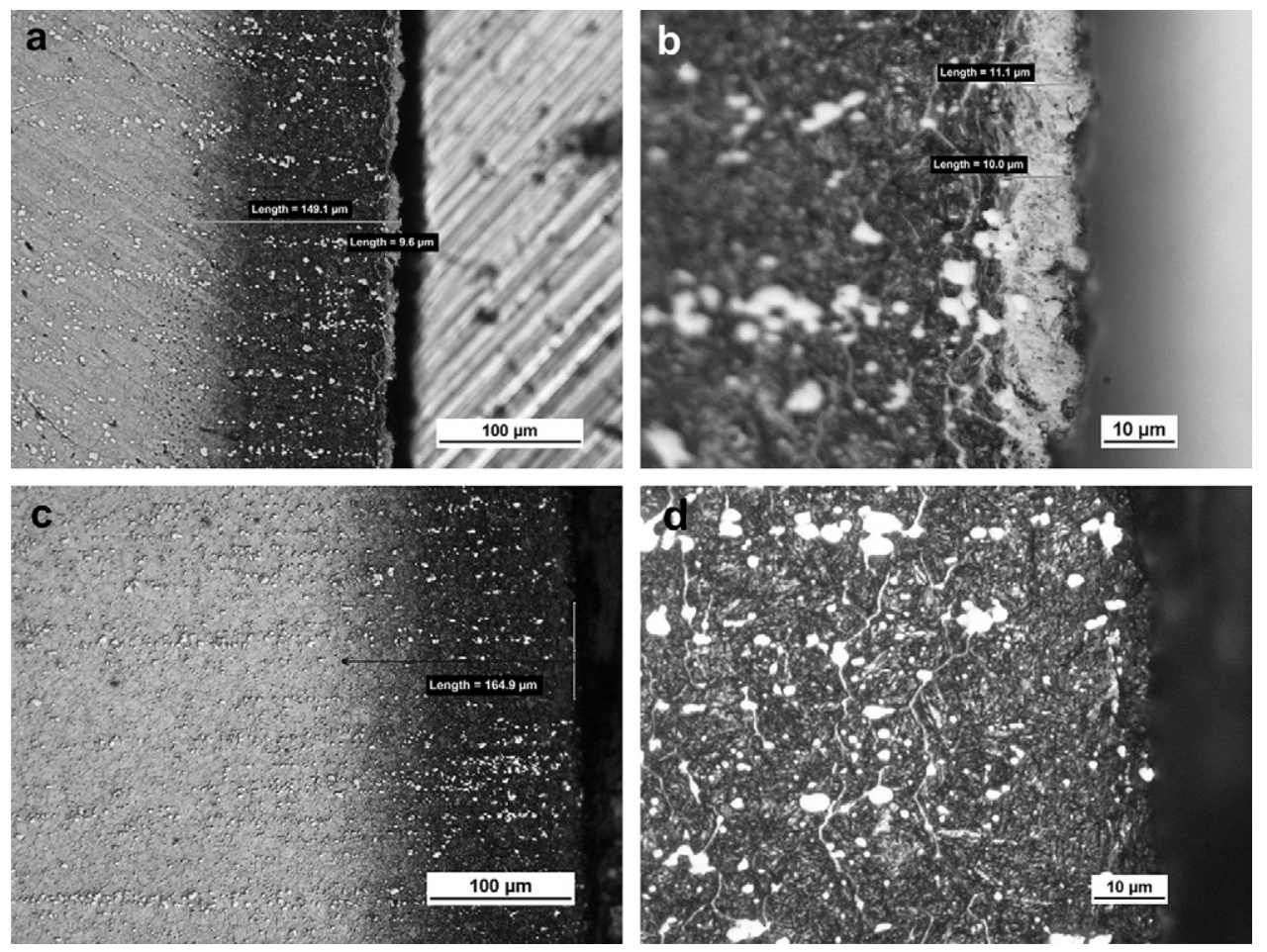

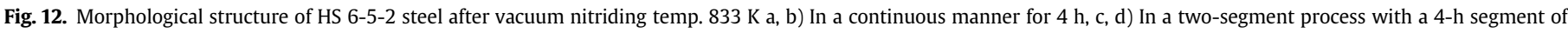
quenching, and a 2 -h segment of diffusion. The surface hardness achieved in the process: $1229 \mathrm{HV} 10$. Optical microscopy images, samples were etched by $4 \% \mathrm{HNO}_{3} /$ ethanol. 
obtain correct structures in the traditional continuous process of low pressure nitriding and, frequently, the structures do not meet the requirements (Fig. 10 a,b and Fig. 12 a,b).

A model employing a neural network was developed with the following conditions:

$\left\{\begin{array}{c}\gamma^{\prime}=0 \div 2 \mu \mathrm{m} \\ \varepsilon=0 \mu \mathrm{m}\end{array}\right.$

The model input values were used to design and run a new process with a 4-h segment of nitriding and 2-h process of diffusion. This resulted in material structures close to the desired ones (Fig. 11).

Another verification of the network operation was conducted for a tool made of HS 6-5-2 steel. The requirements concerned the layer thickness $(0.15 \div 0.18 \mathrm{~mm})$ and absence of nitrogen phases. The results are shown in the figure below (Fig. 12 c, d).

The results obtained with a neural model are very closed to the desired ones. The perfect conformity of the assumptions and the technological result was achieved for HS-6-5-2 steel. The structure of X37CrMoV51 steel contain a non-continuous layer of $\gamma^{\prime}$ nitride, but one which met the thickness requirement; there is a need to increase the number of standards in this case which could teach the network to achieve higher precision of its operation.

\section{Conclusions}

1. Owing to a new approach to low pressure nitriding, based on artificial intelligence methods, it is possible to have a better control over the process, thereby increasing the effectiveness and productivity of the processes.

2. Division into "boost" and "diffusion" stages allows to constitute technological surface layers with complex phase structure, but also without formation of $\varepsilon$ and $\gamma^{\prime}$ nitrides.

3. Employing the method of surface activation results in reducing the time of nitriding processes and guarantees their repeatability.

4. Designing and forecasting the course of the process allows to use vacuum nitriding in precision applications despite their non-equilibrium nature.

\section{Acknowledgements}

Funds for the study have been provided as part of the research grant no. 5216/B/T02/2010/39 "The computer aided system of multi-segment nitrogen hardening of tools in multipurpose vacuum furnaces".

\section{References}

[1] Smolik J, Gulde M, Walkowicz J, Suchanek J. Surface and Coatings Technology (Surface and Coatings Technology) 2004;180:506-11.

[2] Smolik J, Walkowicz J, Słomka Z. High Temperature Material Processes 2004; 8:301-12.

[3] Smolik J, Walkowicz J, Mazurkiewicz A, Tomaszewski J. In: Congress of 14th International federation for heat treatment and surface engineering; 2004. p. 866-869.

[4] Smolik J, Walkowicz J, Brudnias R, Bertrand C, Montero C. High Temperature Material Processes 2005;9:299-306.

[5] Kula P, Korecki M, Olejnik J, Pietrasik R, Wolowiec E. In: Furnaces North America. Orlando; 2010.

[6] Korecki M, Olejnik J, Bazel M, Kula P, Pietrasik R, Wolowiec E. In: The 3th International conference on heat treatment and surface engineering of tools and dies. Wels, Austria; 2011. p. 161-8.

[7] Soshkin S, Lakhtin Y, Kogan Y. Metal Science and Heat Treatment 1984;26: 521-3.

[8] Smirnow AW, Kuleszow JS. Metałłowiedienije I Tiermiczeskaja Obrabotka Metałłow 1966;5:43-9.

[9] Kryłow WS, Góralczyk EH, Szerbiednickij GW. Metałły 1977;4:175-8.

[10] Kula P, Haś Z. In: The 1st International automotive heat treating conference. Puerto Vallarta, Mexico; 1998. p. 195-200.

[11] Małdziński L, Liliental W, Tymowski G, Tacikowski J. Surface Engineering 1999;15:377-84.

[12] Mittemeijer EJ, Somers M. In: The 10th congress of IFHTSE; 1999. p. 83-117.

[13] Ratajski J, Olik R, Suszko T, Dobrodziej J, Michalski J. Sensors 2010;10:218-40.

[14] Ratajski J, Olik R. Advanced Materials Research 2010;83-86:1025-34.

[15] Haś Z, Kula P, Rybicki M. In: Intern. conf. carbides, nitrides, borides; 1987. p. 130-3.

[16] Haś Z, Kula P. In: Intern. conf. carbides, nitrides, borides; 1984. p. 233-44.

[17] Jung M, Hoffmann FT, Mayr P, Minarski P. In: The 2nd intern. conf. carburizing and nitriding with atmospheres. Cleveland; 1995. p. 263-8.

[18] Haś Z, Kula P. The 2nd intern. conf. carburizing and nitriding with atmospheres. Cleveland; 1995. p. 227-31.

[19] Malinov S, Sha W. Computational Materials Science 2003;28:179-98.

[20] Rosenblatt F. Psychological Review 1958;65:386.

[21] Patterson D. Artificial neural networks. Singapore: Prentice Hall; 1996.

[22] Bishop C. Neural networks for pattern recognition. Oxford University; 1995

[23] Shanno D. Mathematics of Computation 1970;24(111):647-56.

[24] Fletcher R. Practical methods of optimization. 2nd ed. , New York: John Wiley \& Sons; 1987

[25] Shanno D, Kettler P. Mathematics of Computation 1970;24(111):657-64. 